\title{
MEDICAL STUDENTS' PERCEPTION OF LEARNING ENVIRONMENT AT BENUE STATE UNIVERSITY COLLEGE OF HEALTH SCIENCES, MAKURDI, NORTH-CENTRAL NIGERIA
}

\author{
Efosa K. Oghagbon ${ }^{*}$, Alexander I. Nwannadi ${ }^{2}$, Godwin Achinge. ${ }^{3}$ \\ Department of Chemical Pathology ${ }^{1}$ and Department of Haematology ${ }^{2}$, Faculty of Basic \& Allied Medical Sciences, College of \\ Health Sciences, Benue State University, Makurdi, Nigeria. \\ Department of Medicine, Faculty of Clinical Medicine, College of Health Sciences, Benue State University, Makurdi, Nigeria. ${ }^{3}$ \\ *Corresponding Author: Efosa K. Oghagbon, Department of Chemical Pathology, Faculty of Basic \& Allied Medical Sciences \\ College of Health Sciences, Benue State University, Makurdi, Nigeria. E-mail: efosaoghagbon@yahoo.com
}

Received date: December, $25^{\text {th }}$, 2017, Accepted date: March $26^{\text {th }}$, 2018. Published date: April $20^{\text {th }}, 2018$

\begin{abstract}
The perception by Medical Students of their learning environment impacts on their understanding of the course of study and performances. This was a descriptive study that assessed medical students' perception of learning environment at the College of Health Sciences, Benue State University, Nigeria. The Dundee Ready Education Environment Measure (DREEM) questionnaire was applied to all the second, third and fourth year medical students to assess the following areas; student's perception of learning (SPL), student's perception of course organizers (SPCO), student's academic self-perception (SASP), student's perception of atmosphere (SPA), and student's social self-perception (SSSP). Data was analysed with the SPSS software version 15. Out of 250 questionnaires distributed to the students, 210 (84\%) were fit for analysis; 174 males (82.9\%) and 36 females (17.1\%) with a mean age of 24.8 years \pm 3.7 . Mean global score (MGS) of study was $106.3 / 200(53.2 \%)$ meaning positive perception, but not reflective of students centred learning. SPCO and SSSP needs to improve at a score of $48 \%$ and $49.3 \%$ respectively as against $100 \%$. Other domains had positive perceptions (SPL; 56\%, SASP; $61.9 \%$, and SPA; 53.5\%). There was a significantly lower SPA score in those in fourth year of study compared to second and third year students. $(\mathrm{p}<0.01)$ Medical Students at the BSU, Nigeria have positive perception of their learning environment, but the authority can improve MGS by increasing students' social support, and retraining the teachers.
\end{abstract}

Keywords; Learning environment, Students' perception, Medical students, Nigeria.

\section{Introduction}

The environment in which undergraduate medical education takes place has been shown to have an impact on the level of success of its students. ${ }^{1}$ Various aspects of this environment have been found to influence the results of effective curricula thus leading to positive outcomes of its graduates. ${ }^{2,3}$ The learning environment is not limited to studentteacher interaction, teaching and learning activities, it also includes physical structures/facilities available to learners. ${ }^{4}$ In addition, such environment involves the provision of support for students' psychosocial and emotional needs. ${ }^{3}$ Given the above components of a learning environment and its impact on study outcome, it is important that managers of such environment understand how students perceive their study space. Such perception may provide information on areas needing improvement or reinforcement in an educational environment, with a view to enhancing student learning outcomes. Evaluation of students' learning environment and use of results from such works have been reported to 
improve the quality of programs in some institutions. 5

This type of assessment is particularly important for medical students training where the expected outcome for a properly trained medical doctor is paramount. The need for better understanding of students' perception of the environment at our medical college and application of possible findings to increase learning outcomes, if need be, informs the present study. The College of Health Sciences, Benue State University, Makurdi is a new medical school in Nigeria and the desire of its management team is to create a conducive educational environment that will culminate in graduation of adequately trained medical doctors.

Medical education at our College of Health Sciences is a six-year programme with the first year spent in the Faculty of Sciences of the University. By the second year, our students commence core subjects of the medical programme beginning with anatomy, biochemistry, and physiology. Subsequent years will involve other subjects (anatomical pathology, medical microbiology, haematology, chemical pathology, Pharmacology \& therapeutics, paediatrics, obstetrics and gynaecology, community health, surgery and internal medicine) with examinations usually written after 3-semester duration of each course, until completion of a minimum of 6 years.

This study will serve as a baseline of students' perception of their learning environment, and may also show impact of gender, age and year of study on various aspects of the environment. It is expected that this study would provide a reference point for future works on the progress or otherwise, in the management of our students learning environment. Such future studies will be needed considering periodic changes in student-body composition and teacher population. ${ }^{3}$

\section{Materials \& Methods}

This descriptive study involved the application of Dundee Ready Education Environment Measure (DREEM) questionnaire to all the Medical Students except those in their first year of study. Two hundred and fifty (250) students in second, third and fourth year of study at the College of Health Sciences, Benue State University, Makurdi, Nigeria completed the 50- items DREEM questionnaire used for this study.

The first year students were excluded from the study because at this level, they are considered to be students of the Faculty of Science. These first year students do not have access to facilities and personnel in the College of Health Sciences, therefore cannot correctly assess the learning environment for the purpose of this study. At the time these questionnaires were distributed, the medical school had students in fourth year and below, hence we here report perception by students in their second to fourth year of study.

Ethical clearance for the study was obtained from the Institution Review Board, Benue State University Teaching Hospital, Makurdi, Nigeria. The students were first briefed on the essence of the project and made aware of their right to either participate or decline the study without any punitive measure taken against them. Once this was clear, the questionnaires were distributed to them during the last 20 minutes of their respective classes. All the participants were given the option of either filling the questionnaires in the class or take them to their homes and return the filled form the next day to the Secretary/research assistant of the lead researcher. Efforts were made to ensure that it was difficult if not impossible to ascertain which student completed a particular questionnaire. This was achieved by not expecting names or any other student identity information such as matriculation numbers to be filled in the questionnaire. Another method we used to ensure student anonymity was asking them to drop completed questionnaires in a dedicated box which was opened for retrieval after they were all submitted.

The DREEM instrument is a validated Likert-type inventory tool which has the advantages of selfadministration to respondents and usefulness in assessing a particular learning environment. ${ }^{6,7}$ There are five major domains in the questionnaire with each area specifically measuring an area relevant to the assessment of learning environment. The domains are; students' perception of learning; SPL, (12 items with a maximum score of 48), students' perception of course organisers; SPCO, (11 items with a maximum score of 44), students' academic self-perception; SASP, (8 items with a maximum score of 32), students' perceptions of atmosphere; SPA, (12 items 
with a maximum score 48) and students' social selfperception; SSSP, (7 items with a maximum score of 28).

According to the DREEM questionnaire scoring formula, each item is scored from 4-0 (4 = strongly agree, 3 = agree, 2 = unsure, $1=$ disagree, and $0=$ strongly disagree) by the respondents on a five-point Likert scale. The instrument has an overall score of 200, signifying the ideal educational environment as perceived by students. ${ }^{8}$ The breakdown of the scoring system is attached as annexure 1 .

The completed questionnaires were then sorted to identify those that were completely filled and incomplete questionnaire were excluded from analysis. Anonymised responses were entered into a database. Data analysis was performed using SPSS (Statistical Package for Social Sciences) version 20. Student $t$ test was used to find out the difference between the mean scores, with the point of significance set at $P<0.05$.

\section{Results}

Of the two hundred and fifty questionnaires administered to the students, two hundred and ten were returned fully completed and fit for analysis, thus producing a study-response rate of $84 \%$. Of the outstanding 40 questionnaires not included in the study, thirty-four were not returned while six were returned uncompleted.

The mean age of the respondents was 24.8 year \pm 3.7 , with a range of 18-39 years. One hundred and seventy-four students $(82.9 \%)$ who participated in the study were males and $36(17.1 \%)$ were females (see Table 1).

The DREEM questionnaire in the studied students' population demonstrated an internal consistency and validity with a calculated Cronbach alpha factor of 0.79 . It is accepted that an alpha factor of 0.70 is consistent with valid internal consistency. ${ }^{9}$ The global average score of this study was 106.3/200 $(53.2 \%)$ which is interpreted as a "more positive than negative perception". There was no significant difference in the overall scores with regard to gender $(\mathrm{p}=0.12)$, age $(\mathrm{p}=0.44)$ and year of study $(\mathrm{p}=0.12)$ of the students, at $\mathrm{p}<0.05$. Table 3

As shown in Table 2, the subscale mean scores analyses for the Student's Perception of Learning was 26.9/48 (56\%); "A more positive perception", Student's Perception of Course Organizers was 21.1/44 (48\%); "In need of some retraining" and Student's Academic Self-Perception was 19.8/32 (61.9\%); "Feeling more on the positive side". The score for Student's Perception of Atmosphere was 25.7/48 (53.5\%); "A more positive attitude" and that of Student's Social Self Perception was 13.8/28 (49.3\%); "Not a nice place to study".

It was observed that the Students' Perception of Atmosphere average score for students in fourth year $(24.3 \pm 6.0 ; 49.7 \%)$ of study was significantly lower than in those of third $(27.5 \pm 6.5 ; 54.5 \%)$ and second year $(26.6 \pm 6.5 ; 54.6 \%)$ using Anova calculation $(\mathrm{p}$ $=0.009)$ at $\mathrm{p}<0.05$. Table 3 . The effect of gender, age and year of study was not significant in the other aspects of the learning environment.

Table1: Age, sex and year of study distribution of the respondents

\begin{tabular}{|c|c|c|c|c|c|}
\hline \multicolumn{2}{|c|}{ Age } & \multicolumn{2}{|l|}{ Gender } & \multicolumn{2}{|c|}{ Year of study } \\
\hline Age range & $\mathrm{n}(\%)$ & & $\mathrm{n}(\%)$ & & $\mathrm{n}(\%)$ \\
\hline $18-23$ & $89(42.4)$ & Male & $174(82.9)$ & Second year & $63(30.0)$ \\
\hline $24-29$ & $94(44.8)$ & Female & $36(17.1)$ & Third year & 46 (21.9) \\
\hline $30-35$ & 25 (11.9) & & & Fourth year & $101(48.1)$ \\
\hline $36-39$ & $2(0.9)$ & & & & \\
\hline Total & $210(100.0)$ & & $210(100.0)$ & & $210(100.0)$ \\
\hline
\end{tabular}

$n=$ number. Male to female ratio $=5: 1$. 
Table 2: Mean perception scores in the DREEM questionnaire global and sub-domains

\begin{tabular}{|c|c|c|c|c|}
\hline & & Mean score (SD) & $\begin{array}{l}\text { Maximum } \\
\text { score }\end{array}$ & Interpretation \\
\hline & Mean global score & $106.3(19.2)$ & 200 & a "more positive than negative perception \\
\hline$\checkmark$ & Student's Perception of Learning & $26.9(6.3)$ & 48 & a more positive perception \\
\hline$\checkmark$ & $\begin{array}{l}\text { Student's Perception of Course } \\
\text { Organizers }\end{array}$ & $21.1(5.2)$ & 44 & in need of some retraining \\
\hline$\checkmark$ & $\begin{array}{l}\text { Student's Academic Self- } \\
\text { Perception }\end{array}$ & $19.8(5.2)$ & 32 & feeling more on the positive side \\
\hline$\checkmark$ & $\begin{array}{l}\text { Student's Perception of } \\
\text { Atmosphere }\end{array}$ & $25.7(6.3)$ & 48 & a more positive attitude \\
\hline$\checkmark$ & Student's Social Self Perception & $13.8(4.4)$ & 28 & not a nice place \\
\hline
\end{tabular}

The above table shows that Student's Perception of Course Organizers and Student's Social Self Perception (SPCO and SSSP) are areas of notable negative perceptions by the students of the BSU, College of Health Sciences that may need immediate attention. These domains scores may be contributory to the relatively low MGS (53.2\%) of the medical school.

Table 3: Influence of age, gender, and year of study on the mean global and subdomain scores

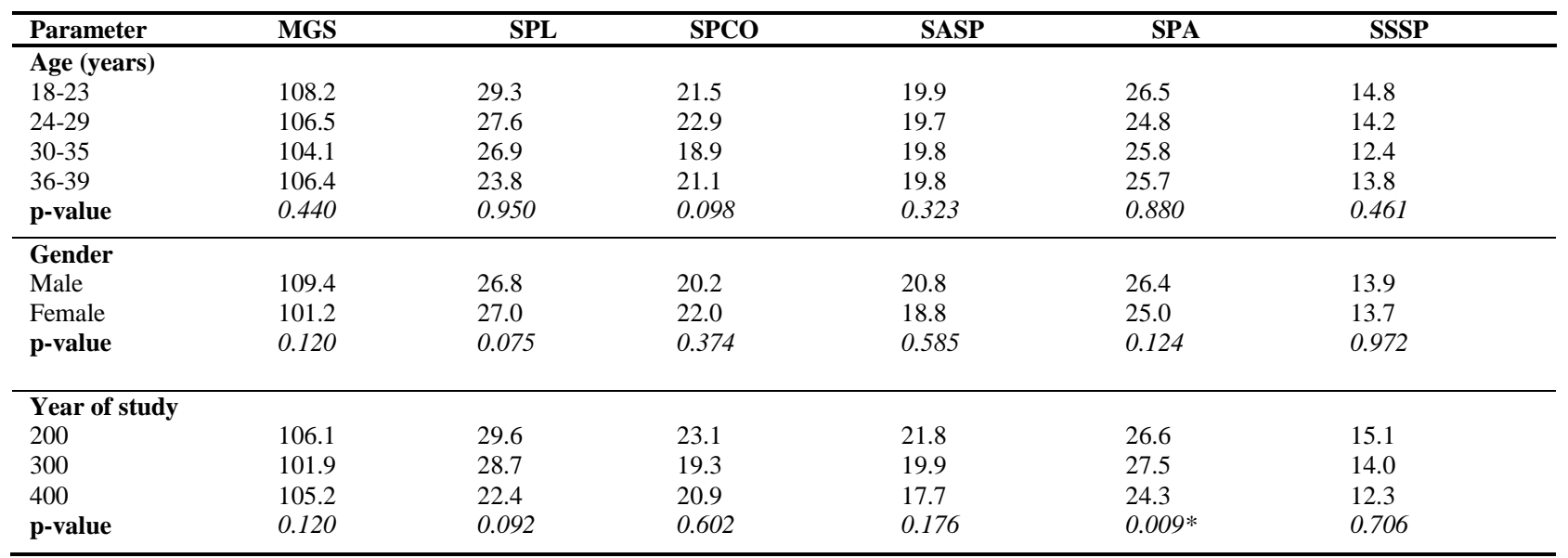

Key: MGS-Mean Global Score, SPL-Student's Perception of Learning, SPCO-Student's Perception of Course Organizers, SASP-Student's Academic Self-Perception, SPA-Student's Perception of Atmosphere, SSSP-Student's Social Self Perception. *significant

\section{Discussion}

The response by the students to the study was commendable. This is possibly a reflection of their expectations of study implication for their learning space. A high response rate of $84 \%$ as found in this study is similar to those reported in some other studies ${ }^{1-3}$ in which the authors suggested was due to students expectations that the results of such studies will impact positively on their learning environment. It is reasonable therefore to expect students to be positive partners in affairs that will address their education environment and potentially their learning experiences and outcomes.

The study global average score of 106.3/200 (53.2\%), is rated as "more positive than negative" according to the scoring mechanism of the DREEM questionnaire tool. This level of positive perception was found to be consistent across the ages, gender and year of study of the students, and this is shown in Table 3. However, the positive perception value of the students at the Benue State University Medical
School is less than those reported from similar studies, especially in developed countries. ${ }^{10,11,12}$

A positive perception score of $78 \%$ was reported in a work done in a Scandinavian College of Chiropractic Medicine Sweden. ${ }^{10}$ and $71.5 \%$ was recorded at the School of Medicine, University of East Anglia, in the United Kingdom. ${ }^{11}$ The study in East Anglia noted the impact of year of study on students' perception score as they observed higher value in first year medical students. The reason suggested for this is that this category of students are likely to be excited at gaining admission to medical school and may not have stayed long enough to adequately and objectively respond to the various components of the DREEM questionnaire. The present study did not include first year medical student as the least level of respondents were those in their second year of study. In the students' assessed in this study, the East Anglia observation was not repeated as there was no 
significant difference in the perception scores in relation to year of study. At the BSU, Makurdi, Nigeria; like in all medical schools in the country, the first year students are taught and assessed by the Faculty of Science of the university. It is after they complete the first year and meets the criteria to proceed to the second year which is at the College of Health Sciences, that they are considered being in the medical school. Until their second year of study, they are not accommodated in the medical students' hostel which is usually separate from that of the main university.

In a similar study in Birmingham, England, ${ }^{12}$ that involved students at multiple teaching sites of eight teaching hospitals, the authors reported a lower student perception score (69.5\%) than those of East Anglia and Sweden mentioned above, but its value is still higher than ours. The high value of students' perception of their learning environment in some developed countries could be attributed to the availability of modern educational systems. ${ }^{10,11,12}$ The observation of high scores of students perception of learning environment is not only restricted to developed economies. In studies done in Nepal, ${ }^{13}$ and Malaysia,${ }^{14}$ global students' perception of learning environment scores of $65 \%$ and $61 \%$, respectively were obtained. This relatively high global score of students' perception of learning environment has found to be associated with the adoption of innovative curricula which is student focused, as opposed to the traditional teaching approach that has reduced student-teacher interaction. ${ }^{15}$ This traditional system of medical education has been observed to be responsible for the low scores of students' perception of learning in $\operatorname{Iran}^{16}$ and Saudi Arabia ${ }^{17}$ where the authors reported mean scores of $49.8 \%$ and $51 \%$, respectively.

It is demonstrated that medical schools operating traditional teaching system, commonly have perception of learning environment scores below 120 (60.0\%). A mean overall perception score of $53.7 \%$ was obtained at Kasturba Medical College in India ${ }^{18}$ and this is comparable to the mean score of $53.2 \%$ in our study. Though these values suggest good perception by the DREEM questionnaire rating, managers of education environment, especially medical school should aim to score higher marks as values less than $60 \%$ has been found to reflect level of curricula innovations. This position was elaborated in an article by Kiranet $a l,{ }^{19}$ where it was noted that schools with innovative curricula tend to report higher scores on DREEM.

The overall mean score of $53.2 \%$ recorded in our study may be attributed to the use of the traditional system of education. In some environment this model does not actively engage the students due to didactic methods of presenting lectures and tutorials. The traditional education system does not focus on student's individual needs and, self-learning and expression by the students are not emphasised. It is encourages rote learning and memorization with little spontaneous student-to-teacher communication. ${ }^{20}$ Unlike innovative or students' centred method which encourages active learning, knowledge seeking behaviour and increased peer to peer learning. ${ }^{22}$

In the present study, the highest score 19.3 out of a total of 32 points $(61.8 \%)$ was recorded in Student's Academic Self-Perception domain. This subscale score reflects the level of self-confidence of the students with a score of $61.8 \%$ clearly demonstrating that trait. There was no significant difference in Student's Academic Self-Perception with regard to age, gender, and year of study. Similarly, high score of academic self-perception has been recorded in most schools in the UK. ${ }^{6}$ In contrast, a low score for the same assessment area has been reported in Canada in work carried out at the University of Columbia. ${ }^{19}$

Our students' perception of course organisers score was found to be low at 21.1/44 (47.9\%) and this according to DREEM questionnaire ranking means the teachers at Benue State College of Health Sciences will benefit from some retraining. The areas in which the course organisers may need to pay attention includes, the students feeling of being ridiculed and not enough being provided adequate feedback. Another source of worry to the students is that the course organizers do not provide constructive criticisms to the students. The issues raised by the students' responses in their perception of course organisers or teachers could be managed with proper training of the teachers in order to address noted shortcomings. This training should include orientation of the teachers on better teacher-student communication skills.

Unlike in our study, there was more positive perception of teachers by students at the University of British Columbia, Canada. ${ }^{19}$ This positive 
perception was attributed to the use of innovative curricula and technologies that enhance studentteacher interactions within the broad scheme of student focus agenda. ${ }^{23}$ Also, low SPCO have been attributed to teachers being considered authoritarian by students and thus affect negatively student-teacher interactions. $^{10}$

Student's Social Self Perception was another aspect of the learning environment that had a low score in our study 13.8/28 (49.3\%). The interpretation for this is that it is "not a nice place" for learning. The social self-perception score varies from place to place and reported score varies from 45 to $72 \%{ }^{24-30}$ The low score in SSSP at BSU medical school maybe due to paucity of support system for students who are stressed. This is likely to be responsible for a high response rate of not enjoying the course or being bored by it, by the students. It might be beneficial, if students, especially higher level students have access to stress management schemes to help them cope with perceived stressors.

The stress may be one of the factors responsible for students at the fourth year of study having significantly lower Student's Perception of Atmosphere score than those at third and second year. The fourth year students are more likely to have been exposed to more rigorous academic works associated with medical education. Though we are not sure what the contribution of the traditional method of teaching is to the level of perceived stress by the students, it may be a factor worth considering in future studies. It is advised that the authority of the medical school device measures to help allays the stress of medical students in the course of their study and this may go a long way in attenuating their present perception of learning atmosphere.

Students at the College of Health Sciences, Benue State University have a somewhat positive perception of their educational environment, but their teachers and social self-perceptions are weak areas needing further attention. If these observed shortcomings are managed effectively, especially with introduction of student-focused education, there may be markedly improved perception of the learning environment in the medical school.

\section{Conclusion}

The overall perception of the learning environment by the medical students was $53.2 \%$ which reflects more positive than negative. The sub domains of Student's Perception of Course Organizers and Student's Social Self Perception (SPCO and SSSP) are areas needing attention. The teachers need retraining and the College management should imbibe students' centred and innovative curricula to make the environment more learning friendly.

\section{Acknowledgement}

This work was supported by the Tertiary Education Trust Fund (Tetfund), Nigeria in their 2016 funds allocation;TETFUND/DESS/UNI/MAKURDI/RP/V OL.IV.

\section{References}

1. Menaka DS, Sachini P, Ranawakaarachchige IR, Heethaka TR, Harshima D.Students' perception of the educational environment in a Medical Faculty with an innovative curriculum in Sri Lanka. South-East Asian J Med Educ.2010; 4(1): 9-16

2. Abraham R, Ramnarayan K, Vinod P, Torke S: Students' perceptions of learning environment in an Indian medical School. BMC Med Educ. 2008; 8(20): 1-5.

3. A Study of Learning Environments in the Kulliyyah (Faculty) of Nursing, International Islamic University Malaysia. Malays J Med Sci. 2009; 16(4): 15-24.

4. Harden R. The learning environment and the curriculum. Med Teach. 2001; 23: 335-336.

5. Pimparyon $\mathrm{P}$, Roff $\mathrm{S}$, McAller S, Poonchai B, Pemba S. Educational environment, student approaches to learning and academic achievement in a Thai nursing school. Med Teach. 2000; 22: 359-364.

6. Roff S, McAleer S, Hardeen R, Al-Qahtani M, Ahmed A, Deza H, et al. Development and validation of the Dundee Ready Education Environment Measure (DREEM). Med Teach. 1997; 19: 295-9.

7. Edgren G, Haffling AC, Jakobsson U, McAleer S, Danielsen N. Comparing the educational environment (as measured by DREEM) at two different stages of curriculum reform. Med Teach. 2010; 32: 233-238.

8. McAleer S, Roff S. AMEE Education (Dundee). Part 3: A practical guide to using the Dundee 
Ready Education Environment Measure (DREEM). In: Genn JM, editor. Dundee, UK: Association of Medical Education in Europe; 2002. Guide No. 23: Curriculum, environment, climate, quality and change in medical education: a unifying perspective.

9. Nunnaly JC. Psychometric theory New York: McGraw-Hill; 1978.

10. Perception of Educational Environment among Undergraduate Students in a Chiropractic Training Institution. J Chiropr Educ. 2011; 25(2): 151-163.

11. Miles S, Leinster SJ. Medical students' perceptions of their educational environment: expected versus actual perceptions. Med Educ. 2007; 41(3): 265-272.

12. Varma R, Tiyagi E, Gupta JK. Determining the quality of educational climate across multiple undergraduate teaching sites using the DREEM inventory. BMC Med Educ. 2005; 21: 5(1): 8.

13. Roff S, McAlear S, Ifere OS, Bhattacharya S. A global diagnostic tool for measuring educational environment: comparing Nigeria and Nepal. Medical Teacher 2001; 23: 378-82.

14. A Study of Learning Environments in the Kulliyyah (Faculty) of Nursing, International Islamic University Malaysia Malays J Med Sci. 2009; 16(4): 15-24.

15. Hammond SM, O'Rourke M, Kelly M, Bennett D, O'Flynn S. A psychometric appraisal of the DREEM. BMC Med Educ. 2012; 12(2): 1-5

16. Medical students' perceptions of the educational environment at an Iranian Medical Sciences Universit BMC Med Educ. 2010; 10(87): 1-7

17. Perceptions of the educational environment of the medical school in King Abdul Aziz University, Saudi Arabia. Med Teach. 2004; 26(6): 570-573.

18. Mayya S, Roff S. Students' perception of educational environment: a comparison of academic achievers and under-achievers at Kasturba Medical College, India. Educ Health Change Learn Prac. 2004; 17: 280-291.

19. Kiran V, Sean M. Student perception of the learning environment in a distributed medical programme. Medical Education Online. 2010; 15(5168): 1-10.

20. Upasana KM. A comparative study of traditional education and e-education with special reference to India. IMPACT: IJRBM. 2014; 2(5): 149 162.

21. Thomerson JD. Computer-assisted instruction vs. traditional instruction in an advanced-level computer course. Issues in Information Systems. 2006; 7(1): $114-118$.

22. Benè KL, PhD; Bergus G. When Learners Become Teachers: A Review of Peer Teaching in Medical Student Education. Fam Med. 2014; 46(10): 783-787.

23. Freeman M. Video conferencing a solution to the multi campus large classes' problem? Brit J Educ. 1998; 29: 197-210.

24. Ted Brown, Brett Williams, Marty Lynch. The Australian DREEM: evaluating student perceptions of academic learning environments within eight health science courses. Int J of Med Edu. 2011; 2: 94-101.

25. Roff S. The Dundee Ready Education Environment Measure (DREEM)-a generic instrument for measuring students' perceptions of undergraduate health professions curricula. Med Teach. 2005; 27: 322-325.

26. Till H. Climate studies: can students' perceptions of the ideal educational environment be of use for institutional planning and resource utilization? Med Teach. 2005; 27: 332-227.

27. Bassau B, Roff S, McAleer S, Roopnarinesingh $\mathrm{S}$, Lisle JD, Teelucksingh S, et al. Students' perspectives on the educational environment, Faculty of Medical Sciences, Trinidad. Med Teach. 2003; 25: 522-526.

28. Jiffry MTT, McAleer S, Fernando S, Marasinghe RB. Using the DREEM questionnaire to gather baseline information on an evolving medical school in Sri Lanka. Med Teach. 2005; 27: 34852.

29. Dunne F, McAleer S, Roff S. Assessment of the undergraduate medical environment in a large UK medical school. Health Educ J. 2006; 65: 149-158.

30. Al-Hazimi A, Zaini R, Al-Hyiani A, Hassan N, Gunaid A, Ponnamperuma G, et al. Educational environment in traditional and innovative medical schools: a study in four undergraduate medical schools. Educ Health. 2004; 17: 192203. 